\title{
Low-cost domestic water filter: The case for a process-based approach for the development of a rural technology product
}

\author{
VCS Prasad \\ Tata Research Development and Design Centre, 54 B Hadapsar Industrial Estate, Pune, 411004, India
}

\begin{abstract}
The paper describes the case of development of a rural technology product in a high-technology IT (information technology) environment. The product is a low- cost water filter for which there is a definite need in rural India. The case brings out how even a simple- looking concept for water filtration has to go through several well-defined steps for successful introduction into the field. These evolutionary steps resulting in a process for product development were found to be not too different from any high-technology product process (including a software product process) leading to the inference that in general the steps for a successful product process are the same whether the end use is for a high -technology application or a low- technology application. The usefulness of carrying out work within a process framework is highlighted. Since the project aims at technology transfer to the rural poor for generating rural livelihoods, appropriate financial models and the general sustainability issues for such an activity are briefly discussed. The usefulness of an IT environment in facilitating the development activity is pointed out. The lessons learnt in this exercise are documented.
\end{abstract}

\section{Introduction}

Tata Research Development and Design Centre (TRDDC) is one of India's leading $R \& D$ centres in the private sector. It is the research division of Tata Consultancy services (TCS) and is situated in Pune. TCS is Asia's largest independent IT company having its corporate office in Mumbai, India. Its activities are spread over several centres both in India and overseas. TCS is one of the highly successful companies of the TATA group, the largest industrial conglomerate in India having presence in very diverse areas such as steel, automobiles, chemicals, advanced materials, watches, tea, finance, etc. in addition to IT.

TRDDC was conceived as a contract R\&D and consultancy organisation to start with when this work was initiated. The centre also has provision for some limited in-house funding for certain selected projects. The currently described activity is supported by such funds although initial R\&D work which resulted in the demonstration of the basic concept was funded by an international agency, IDRC, Canada.

TRDDC has an interdisciplinary team of scientists and engineers. It has broadly two divisions, namely process engineering and software engineering. The process engineering division has three groups: Process Modelling, Minerals and Materials and Rural Technology. The core strength across these groups, however, is mathematical modelling of processes.

The rural technology group works on the use of waste materials for developing processes and products for rural needs. Currently two areas are receiving major attention, one being the use of rice husk ash (rice husk is available in large quantities in rural India) for low-cost water filters and the other, use of rural waste to cater to the energy needs of the villagers through the biogas and gasification

용+9120687 1058; fax: +91206810921;

e-mail: vcsprasad@pune.tcs.co.in

Received 24 July 2001; accepted in revised form 4 January 2002. route. The present paper deals with the first area, viz. use of rice husk ash for the fabrication of low-cost water filters on which a couple of patents were filed by TRDDC.

According to the recent WHO (World Health Organisation) assessment (Mathys, 2000), there are at least $5 \mathrm{~m}$. deaths/yr due to the use of unsafe drinking water and at least 1.4 bn do not have access to drinking water. To address such a gigantic problem, novel technical, managerial and financial solutions are required. The work reported in the present paper is one such attempt.

The paper first outlines the experiences and difficulties in taking a technical solution to the field. Based on these experiences an attempt is made to evolve a generic process for this activity. Considering that the beneficiary of the invention is rural India adds an additional significance to this effort and more so that a good part of this effort was supported by a leading IT company, viz. Tata Consultancy Services, India.

\section{Background}

Rice-husk ash (RHA) as a filtration medium for water is fairly well known (Frankel, 1979); however, the use of RHA for designing a usable filter element for domestic filtration in rural homes is new. TRDDC, Pune has done extensive research in this area and has filed two Indian Patents for this application, (Sundaram et al., 1997), (Meher and Prasad, 1999). The patents describe the materials, the composition, and the processing details for the fabrication of the filter element and the container designs. The filter is called a pebble matrix filter (PM filter).

A schematic of an initial filter design used by the inventors is described in Fig. 1. The process of making the filter element involves thorough mixing of RHA, pebbles and cement in required proportion along with water to the consistency of a concrete mix. The mix was rammed into a sanitary-ware pipe closed at the bottom end with a nylon mesh (placed on a tray to have a hard surface for ramming). After ramming, the top end of the bed is also covered 


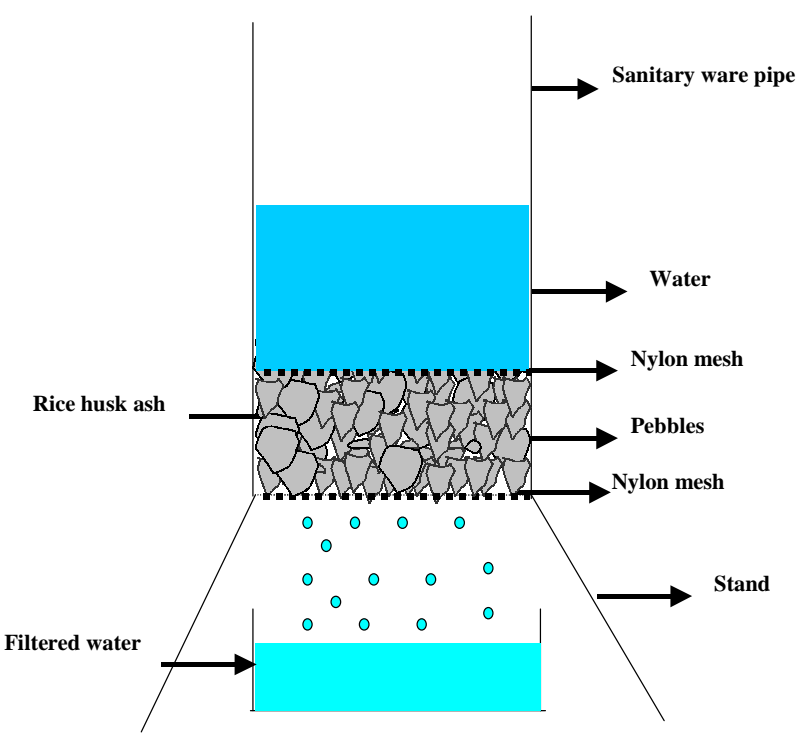

Figure 1

Schematic of the original filter design with the nylon mesh. The mesh stops the fine ash coming out of the filter element. The setting characteristics of the cement imparts the necessary strength to the element.

The output characteristics measured for this filter are bacterial trapping, turbidity, $\mathrm{pH}$ and filtration rate. The best trapping efficiency for bacteria and turbidity is found to be $99 \%$ under certain laboratory conditions. However, there was considerable variation of this value from filter to filter when produced in larger numbers and it is one of the challenges of the project to understand and control the variation so that a realistic tolerance can be given for the trapping efficiency of bacteria and turbidity. The filtered water, though not strictly of WHO standard for bacteria (Huntwork et al., 1993) is expected to be useful in rural India considering the immunity level of the villagers. This is because the general bacterial level of drinking water in a typical village taken on a sample basis varies in the range of 1000 to $10000 \mathrm{MPN} / 100 \mathrm{ml}$ (MPN/100 ml is the unit of bacteria meaning most probable number of bacterial colonies in $100 \mathrm{ml}$ of water) and the water from the above type of filters has a bacterial level of 100 to $200 \mathrm{MPN} / 100 \mathrm{ml}$.

While the basic R\&D activity leading to the demonstration of the concept was complete in the early 1990s, planned development activity started only in the late 1990s. In between, the activity was only sporadic. During this period, although, there was a general interest from the centre management towards this activity, significant oversight from corporate management (the main stakeholders for this work )was not apparent. The work during this time centred around carrying out R\&D on several of the loose ends left earlier and studying alternative technologies using RHA itself for the intended purpose. These studies have only indicated the need for substantial additional $R \& D$ with planned and committed resources for extending the technical capabilities of the basic process.

The first planned development activity took place in the year 1997 after a high-level review team consisting of several experts and the deputy chairman of the company endorsed the importance of this kind of work and suggested fast proliferation of this activity in rural areas. Following this meeting, a small team of two people spending part of their time towards this project, developed some prototypes, installed them in 3 nearby villages and collected field data over several months. The team submitted its report to management in late 1998 summarising the field findings, the pros and cons of different options available for proliferation and the additional time required to implement these options. However, due to changes in the management at the research centre, the decision of whether or not to implement these options took some time. The final decision that the project should be aimed only towards a social objective without any commercial motive came forth in early 2000 when there was also augmentation of resources (largely manpower) for speeding up the activity.

\section{Identification of development issues}

Since rice husk is easily available in rural India, and the process is very simple and inexpensive, it was originally felt by the inventors to offer the process as "do it yourself type" in individual village homes as one of the solutions for providing safe drinking water. To carry out this idea further into the field, the work was given to a development team. 
The development team, after careful study, outlined the process in detail as shown in the flow sheet (Fig. 2). The filter-making process was essentially found to consist of three subprocesses, viz. preparation of the raw material, preparation of the container and the actual filter element fabrication.

It was quickly realised that the "do it yourself mode" as was conceived originally by the inventors is difficult to implement for the following reasons. It is difficult:

- for each home to procure the materials and establish the manufacturing facilities;

- to carry out all the steps indicated in the flow sheet in each individual house;

- to replace the bed once its life is over;

- to maintain the quality every time the filter is made by all those who attempt to make it;

- to make it economically viable and therefore sustain the motivation to continue the activity.

Other issues which needed attention, are:

- Deciding on the type of prototype to be used for trials.

- Justifying the safety of the filter for use considering that the filter does not trap the bacteria completely.

- Convincing the villagers to use the filter

- Deciding the strategy for proliferation.

- Convincing the management about the justification for substantial additional activity and resources required, however simple the idea looks. In fact simplicity has become one of the main problems to convince the management of the magnitude of additional work involved.

- Motivating the scientists towards this kind of low-technology work amongst a plethora of high-technology model-based activities in the centre using high-performance PCs.

From the process flow sheet as well as from the several anticipated difficulties and problems indicated above, it became clear that the process is not as simple as originally thought and particularly for implementing it in the "do it yourself mode ". An alternative proposed strategy is "centralised production at the village level".

Further, a careful examination of the invention reveals that the invention was confined merely to the materials-related issues and not to other important issues such as the container design and looks (non-functional issues) which the customer (villager) can consider equally important (as indeed was observed during prototype trials)

The following issues were therefore identified for further work:

- Design of the filter container keeping in view easy maintenance, usability, cost and reliability. These issues had not been studied while the original concept was demonstrated.

- Design of the process which involves minimum machinery and tools and does not need the use of power for running it (since the process is to be carried out in rural India which may or may not have access to power).

- Establishing realistic tolerance for the filter characteristics so as to have the confidence in the filter performance when produced and used in different environments.

- Data on other filters in the market for comparative analysis.

- Strategy for proliferation

- Strategy to contain costs since the final product is to be at an affordable cost to the villager.
At the beginning, up-front commitment of adequate resources for this activity was found to be difficult because of the feeling that not much is left to be done after the successful demonstration of the concept.

\section{Trials with prototypes}

Early prototyping is one of the effective steps in understanding the user requirements (of late) more so in the software industry (Gabriel, 1999). This concept has been used in the present case for designing an appropriate container.

The prototype consisted of changing the sanitary-ware pipe with a lighter-mass plastic container having a closed bottom to ensure better ramming. Considerable field data were obtained using this prototype.

\section{Identification of critical dependency}

One of the key issues for successful prototype trials was found to be the identification of suitable NGOs (non-government organisations) in whom the villagers have confidence and respect. It was not easy to find such NGOs because quite a few of them wish to carry out this work as a sponsored project, particularly those used to large international sponsorships. Relatively low-profile NGOs do not have the required experience and infrastructure to be of use. Fortunately, it was possible to enthuse a few NGOs to lend support to this activity who used all their credibility with the villagers to make them buy the filters for a nominal cost for trial purposes (It was found that supplying them free of charge would not receive the required seriousness for use). To aid this task, a good deal of awareness material was also prepared for demonstration purposes which needed considerable attention and time.

\section{Feedback from prototype trials}

About 10 filters each were installed in three different villages. These villages were different in size, awareness level and standard of living. Continuous use of the filter (for about six month's time) was found only in the larger-size village having a relatively higher level of education. In the other two villages, the usage of the filter was much lower. The filter performance was tracked by collecting data (bacterial and turbidity trapping and filtration rate) of the influent (unfiltered) and effluent (filtered) water from the installed filters. Following is the summary of trials, which gave considerable insight into villagers' preferences and habits.

- Some villages use chlorinated water with nearly zero bacteria obtained from community supplies although the villagers do not seem to like the taste and smell of it (acceptability).

- However, the stored water in individual homes showed considerable bacterial count and the count varies from house to house and time to time the samples are taken.

- One could distinguish low-variation houses from high variation houses both for the influent water as well as effluent water of the filter. Low-variation houses are somewhat clean and relatively better maintained although more data are required to generalise this point (design requirement: good closed system not affected by day-to-day handling and surrounding cleanliness).

- Provision of items like a tap for the filters attracted the villagers (ease of use and handling comfort).

- Some houses used the filtered water exclusively for children (health consciousness). 


\begin{tabular}{|l|l|l|}
\hline \multicolumn{3}{|c|}{ Checklist for product characteristics } \\
\hline Features & $\begin{array}{l}\text { Status of the } \\
\text { original design }\end{array}$ & $\begin{array}{l}\text { Status of the } \\
\text { improved } \\
\text { designs }\end{array}$ \\
\hline $\begin{array}{l}\text { Ease of fabrication and } \\
\text { assembly }\end{array}$ & Poor & Better \\
\hline $\begin{array}{l}\text { Maintenance (filter } \\
\text { element replaceability) }\end{array}$ & Poor & Good \\
\hline Usability & Poor & Improved \\
\hline Reliability & Poor & Better \\
\hline Acceptability (looks) & Poor & Good \\
\hline Durability & Poor & good \\
\hline Affordability & Good & Not so good \\
\hline Security from copying & Highly vulnerable & Same as original \\
\hline
\end{tabular}

- Need for establishing a practical cleaning procedure for the filter became obvious because of the cleaning habits of the villagers (maintenance).

- Some wish to carry the filters to the fields where they work during the day (light weight and ease of transport).

- Less preference for brittle earthen pot containers and more preference for good-looking metal and plastic containers (durability and looks).

- Transparent plastic containers are found to be very effective and attractive for demonstration (functionality and looks).

- Some villagers have shown concern about whether the materials themselves used (ash and pebbles) have bacteria or the bacteria sitting in the filter affect performance (quality assurance).

- Some wish to make use of their existing metal containers, if possible, for the filter instead of investing in new containers (cost).

The words in brackets are the actual requirements in the product developers' parlance indicated by the user. The variety of requirements indicates that the proposed production centres should have enough flexibility.

\section{Improved designs using product checklist}

The above requirements were as far as possible addressed in the subsequent designs. Each design is assessed against a product characteristics checklist shown in Table 1. The improved design consists of a replaceable filter element inserted in a plastic or stainless-steel container. The leakage between the unfiltered and filtered water is arrested through the use of an appropriate rubber washer (Fig. 3).

It can be seen from Table 1 that the original design does not satisfy most of the requirements for a successful product except affordability. The inventors (materials scientists) obviously largely focused their attention on material-related issues (functional characteristics) not giving sufficient attention to the other nonfunctional characteristics as indicated in the table. In fact, it appears that these issues were not considered to be important because the

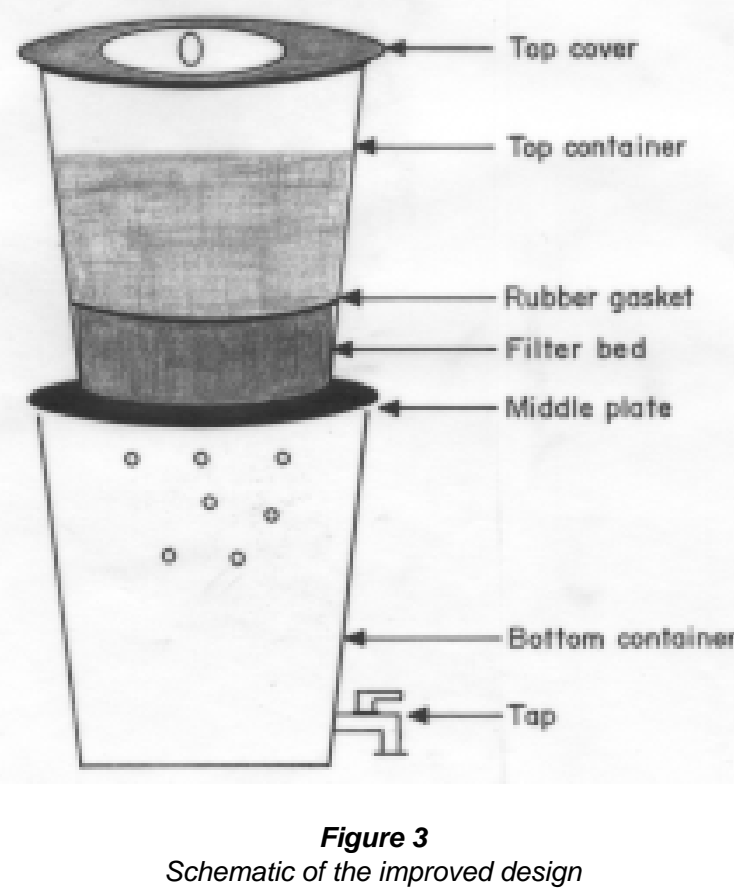

original idea was to introduce the filter as a "do it yourself type in individual village homes". But the product-related non-functional issues are also the requirements of the user and "a requirement is a formal statement of a need and the expected manner in which it should be met" (Pall, 1999). The prototype trials brought out these requirements more clearly.

The problem of security from copying (Table 1) was met through intellectual property (IP) protection (patent filing), which at the beginning of the project was not considered important.

To understand the large variation of filter performance observed during the prototype trials, a systematic quality improvement program for the filter batch process was initiated to minimise the variation in the filter-to-filter characteristics.

\section{Quality issues}

The invention has demonstrated the idea of a filter element trapping nearly 98 to $99 \%$ bacteria and turbidity with acceptable filtration rates when fabricated as single units. But the filter-to-filter variation of the characteristics when produced in reasonable batch sizes (e.g. 10 filters) was not studied and there are several variables causing this variation, which are shown in the cause-and-effect diagram (Fig. 4). Variables like the type of ash, the type of pebbles, the mixing process, the ramming process, testing procedures, etc; influence the output results. It is the identification of the important variables amongst these and their control which enables prediction of a realistic tolerance for the filter characteristics when fabricated in larger numbers in the field. When such a study was done using simple quality tools (cause-effect diagrams and Statistical Process Control (SPC) charts), it was found that the realistic tolerance for the trapping characteristics for bacteria and turbidity was $95 \pm 4 \%$. This result is significantly different from the results of the laboratory studies first made. Use of SPC charts also gave confidence on process stability. This study is important in the present case because it is difficult to monitor the quality of filtered water through expensive bacterial tests when the filter fabrication actually takes place in the villages. A controlled process gives confidence in the output characteristics even if they are not routinely measured. 


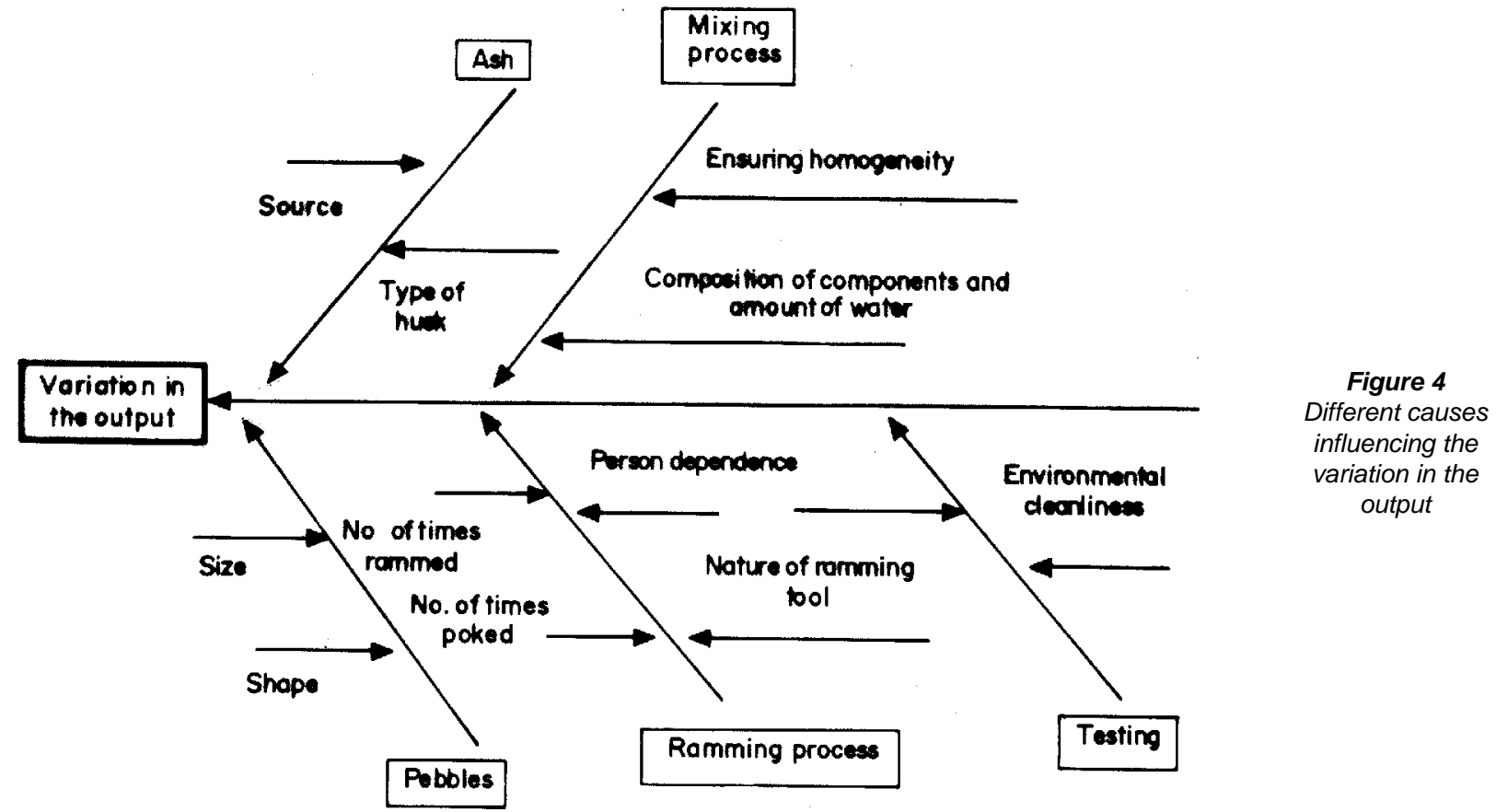

\section{Safety for use}

Since the trapping on an average is only $95 \%$ of the influent levels of bacteria and turbidity, the actual effluent levels in filtered water for bacteria and turbidity depend on the influent levels. For example, if the influent level of bacteria is $500 \mathrm{MPN} / 100 \mathrm{ml}$, the effluent count can be as low as 25 . On the other hand, if the influent level is $5000 \mathrm{MPN} / 100 \mathrm{ml}$, the effluent level is 250 . But, the minimum bacterial count found for the filtered water is $100 \mathrm{MPN} / 100 \mathrm{ml}$, however low the influent bacterial level is. The principle of physically trapping bacteria and the structure of the bed impose this limitation.

The municipal corporation water supplied in cities like Pune (India) has always shown bacterial levels much higher than the above figure $(100 \mathrm{MPN} / 100 \mathrm{ml})$ at the delivery end (although at the supply end this value may comply with the WHO standard) and a good segment of the population drink this water without any further treatment. Contamination of public water supplies is not uncommon even in countries like United States (Kupua, 1998). Therefore, the output from the filter with the above trapping efficiency can be considered to be a safe immunity level. Since the immunity level of the rural population is expected to be much higher, the filter is considered adequately safe for use in the villages.

\section{Comparitive position}

It was originally felt that the extremely low cost of the filter (originally aimed at less than Rs100, 3 US\$) would make the villager take to it automatically but the feedback from the first prototype led to the fact that several additional features (as indicated in Table 1) are to be incorporated in the product to enable ready and regular usage by the villagers. The additional features naturally led to higher initial costs for the product. However, the idea of detachable design for the filter element (Fig. 3) which improves replaceability is expected to have an affordable running cost (estimated at Rs30, less than a US\$). At this point, a careful comparison was made (as given below) for the filter (PM filter) with the existing ceramic candle filters available in the market.

\section{Advantages of the PM filter}

- Turbidity level of filtered water: 2 to 3 times lower $(<0.3 \mathrm{NTU})$

- Bacterial trapping: 10 to $20 \%$ better

- Filtration rate: At least 1.5 times better for the initial few months

- Replacement cost for the filter element: At least 3 times lower

- Clogging rate: Lower for very high turbid water, (>50 NTU)

- Life of the filter for normal water: Comparable

- Design flexibility: High (can be easily fabricated in different sizes)

- Suitability for fabrication in the villages: High

- Scope for livelihood generation in the villages: Good.

\section{Drawbacks}

- Long duration for fabrication (20 to $30 \mathrm{~d}$ ) because of the use of cement as binder but in the village environment this is not considered critical.

- The filter still is relatively heavy (although improved from the original design).

These issues are planned to be addressed through a parallel R\&D program.

\section{Transfer options}

Several options were considered for technology transfer. These include:

- Technology transfer to centralised production units which will manufacture the product on a large scale in selected urban areas and market it in rural areas through established distribution channels.

- Technology transfer to several decentralised units at the village level who will fabricate the product in centralised locations in the villages for use in a few nearby villages. Use of NGOs or other health workers for locating the village-level entrepreneurs for technology transfer. 
- Technology transfer to welfare departments of selected TATA companies who will carry out the proliferation through their already existing well established rural networks

- Technology transfer to companies who are using rice husk as a fuel (example, boilers) so that the waste ash which otherwise has disposal problems can be used to produce value-added products useful for society.

Out of these, the $2^{\text {nd }}$ option has a scope for developing livelihoods in the villages as well as promoting health. Also, fabrication of the filter in the villages reduces the cost of transport, taxes and distribution costs when compared with that of centralised fabrication in towns and cities and their distribution. These advantages can enhance the scope of spread. Therefore, management favoured this option in deciding to offer technology free to interested people who wish to set up village-level units largely with their own means with some help from the Government or the NGOs.

\section{Financial aspects}

It is estimated that fabrication of 50 filters/month is possible with a meagre capital investment of Rs 8000 ( US \$167) and fabrication of 400 filters/month with an investment of Rs 18000 ( US \$375). Therefore, the work can proceed on a small scale to start with, growing in size in course of time. If loans are offered for such an activity, the ROI is found to be sufficiently attractive.

The level of sale depends upon the affordable population level in the villages where the filter is introduced and the effectiveness of the health-awareness programs. Untill a reasonable level of sale is reached, sustainability is difficult to achieve and entreprenuership cannot take off successfully. Therefore initial support is required to see that a reasonable level of sales takes place before the technology is transferred. Once a critical sales figure is reached, sustainability is possible through the replacement (maintenance) market.

Feasibility studies and further refinements of this model are in progress.

\section{Pilot studies}

After generating substantial data as indicated above for design, quality, comparative analysis and financial aspects, a pilot programme was planned with the help of a large NGO organisation (CASP, Community Aid for Sponsored Programs). The objectives of this pilot programme are: Ensuring the acceptability of the filter in large numbers by the villagers (of the order of 500 filters); tracking the health improvements as far as possible, transferring the technology and monitoring the progress for developing rural entrepreneurship which appears to be the only practical means of sustainability for this type of activity.

In addition, a few filters were given to nearby rural hospitals, which have been in use successfully for several months, at the time of preparing this manuscript.

During this time there was an occasion when the chairman of the TATA group of companies visited the centre and requested 500 filters to be sent to Gujarat earthquake victims (There was a devastating earthquake in India in Gujarat in Jan 2001). This order was successfully implemented by the rural technology team and the filters are in use by the earthquake victims.

\section{Discussion}

\section{The need for prototyping}

Although the outcome of the R\&D work, viz. developing a device for providing safe drinking water to the villagers inexpensively addressed an actual need which, in principle, is met through the development of a novel materials solution, it is not sufficient to satisfy the requirements of the villagers. The requirements of the villagers are understood better through interaction with the villagers using prototypes. This has resulted in the use of plastic and metal containers and replaceable filter-element design keeping in view issues like durability, usability, maintenance and even looks. One of the important points that has come out during this exercise is the tendency of the villagers to imitate urban residents in their preferences for looks even if it meant higher cost. Thus the initial idea of supplying the filters with inexpensive and not so goodlooking containers (such as earthenware or sanitary-ware) needed correction. There is a preference for metal containers in some regions because of the habit of storing drinking water in such containers. Thus, although the basic need of providing safe drinking water is met in the original design (which proves the concept), it does not meet several of the requirements of the user (Table 1). Once the need is recognised, the related expectation will have two components: The manner in which the need is to be met and the anticipated benefits to be derived (Huntwork et al., 1993) by fulfilling the need.

Use of high-technology and interdisciplinary skills and the impact of the IT environment: The fact that the high-profile Tata Research Development and Design Centre is engaged in this activity for quite a significant period of time is interesting and made one wonder whether any of its high-technology resources are used for this work. Indeed at several places the high-technology background and the interdisciplinary skills of its members were useful for the work. For example, use of rice husk ash as a filtration medium came from a materials technology background and the new concept of a pebble matrix filter was made possible because of high-level expertise in particulate technology. Filter-testing needed a microbiology background, converting the laboratory invention to the field needed a substantial earlier experience in a somewhat similar activity. In addition, there was a need for design expertise, quality expertise and process-oriented thinking. Simple financial models were developed using the Microsoft Excel package, which helped in arriving at different financial scenarios needed to develop village-level entreprenuership. Standard commercially available statistical packages were also used for SPC charts and other data analysis.

The existing IT environment which is an ISO 9001 company and preparing itself for CMM (Capability Maturity Model) level 5 gave the necessary ambience for process orientation and for the ready use of quality-related concepts. Paperless and fast communication through e-mail was taking place between the members of the project team and the team was using state of the art data-sharing and data-analysis methodologies.

The distant learning programs involving the use of PCs for rural education instituted by Mr. Kohli (of TCS, the parent company of TRDDC) the man who ushered in the IT revolution in India, is an additional incentive expected to help in effectively educating the villagers about health needs, thereby improving the scope of spread of the use of the filter.

Cultural issues: Two types of cultural issues came up during this work which needed careful handling. 
Difference in the type of work from the rest of the hightechnology activities going on in the centre: The core competence of the division is in the area of mathematical modelling of industrial processes. These projects have largely client-driven schedules to which management is generally used to. Compared to this, the activity described in this paper is a relatively low-technology area to which it is difficult to get the commitment and motivation of the team members. The whole process of fabrication of the filter (it involves a curing time of 4 weeks because of the use of cement as a binder), extensive bacterial testing and trying out prototypes in rural areas, is a very slow process to which it was difficult to get the commitment of scientists largely accustomed to sophisticated mathematical modelling and simulation activities and often tested the patience of the management accustomed to the fast-paced IT technology dynamics. Therefore, it became a challenge to get continuous management attention and support for this project. In addition, the work related to development and productisation needed a fair amount of process discipline much more than the actual $R \& D$ work to which the $R \& D$ group is accustomed.

Interacting with NGOs and villagers: The work culture of NGOs and the villagers is different from the IT work culture. Therefore patient understanding and adjustments were required to be able to effectively interact with the NGOs for the implementation activities.

\section{Process assets}

During the present work, a process for patent-to-field has evolved which can act as a guideline for other similar activities. It is clear that this process requires several steps involving considerable time and expense which, for a low technology product such as the current one was always underestimated. The process steps as they evolve during the course of the project are:

- Detailing the process through a flow chart, process design (based on the end-use requirements)

- Understanding customer requirements through prototyping and feedback, product design

- Quality improvements

- Product specification

- Competitive positioning

- Documentation

- Proliferation strategy and plan which includes arriving at appropriate technology transfer methodology and field support.

Figure 5 sums up these steps in a flow sheet. It can be seen from the figure that there are at least 10 well-defined steps between proving the concept and the introduction of the technology into the field. Clear identification and proper definition of these steps help in focusing attention with adequate resource deployment. The first half of the development was done without following such a defined process when there was a considerable hangover of R\&D orientation also. Absence of process clarity resulted in long development times causing frequent embarrassment both to the scientists and the management. In the latter part of the development, however, there was better awareness of the importance of following a process at least as a guideline, which has resulted in focusing on each of the steps resulting in improved productivity. The defined process improved the way the work was done.

For example, for some time, when there was no systematic analysis of the comparative position of the product in a quantitative manner, it was difficult to get the required motivation from team members to carry out the work. Once the advantages became

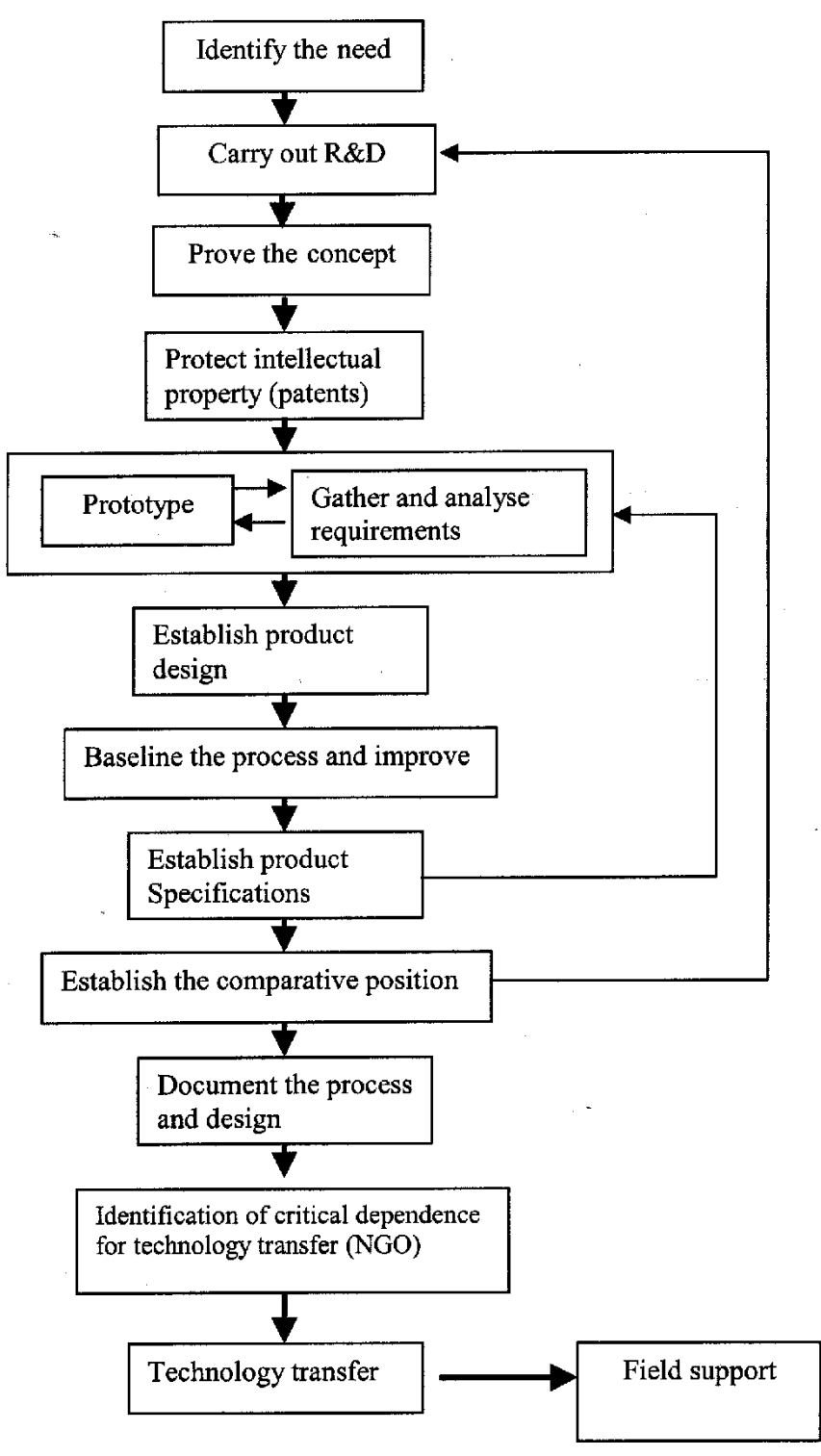

Figure 5

Process flow chart that evolved during the present work to convert $R \& D$ to field

quantitatively clear, the work progressed in a brisk fashion. Similarly, identification of the steps like product design, process base lining and improvement, proliferation plan and implementation gave a clear focus on each of these activities for detailed planning and implementation.

The proliferation/marketing strategy in the flow chart is obviously an important step in the process. For high-technology and urban consumer products there is lot of information based on market research which can give guidance for an appropriate marketing strategy. However, for a rural product such as the current one, similar information is not so easily available. Additionally,. the proliferation strategy involves technology transfer and its effective use by the villagers for their livelihoods. Therefore, guidance in such cases has to come largely from one's own trials.

It is interesting to note that the flow chart in Fig. 5 is somewhat similar to the product process reported by Huntwork et al. (1993) for software products. It is also close to the product life-cycle models that are getting evolved by the software group of the centre 


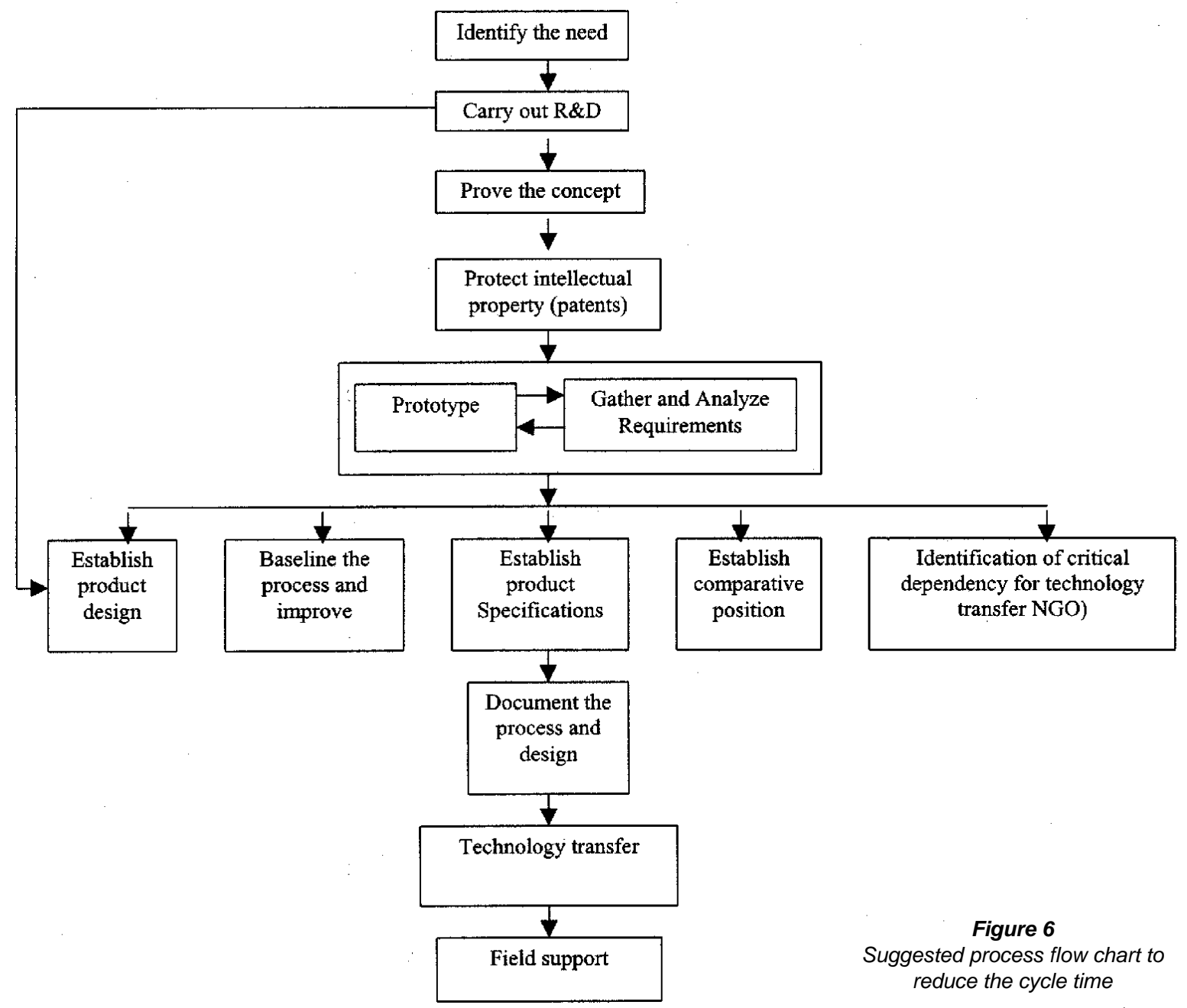

in preparation to the CMM Level5 indicating that a process for successful product development is the same in general irrespective of the fact whether the product is of high technology or low technology.

General project management issues: The most important issue that has often been raised in this project is the unusually long time taken for putting the proven concept into the field considering the fact that the concept is very simple.

Based on the background information provided at the beginning of the paper, it was evident that when the management interest was clearly communicated in the year 1997 (when the high-power committee met), the activity went on in a brisk manner. Similarly, in early 2000, the activity was again brisk with renewed vigour, when management more clearly expressed its vision and expectation from this project. Since the project ran for quite some time in a selfsupporting R\&D environment, some time was also spent on exploring the possibility of commercial returns. But this option was subsequently abandoned.

Although the total duration of the project appeared long (spanning over 7 years), the development activity was never carried out continuously with a focused attention and plan except during the last 3 years as indicated in the background information. Dedicated manpower exclusively towards this project was committed only during this time and more significantly during the last one year. With a process in place right at the beginning, there is good scope to reduce this development time. Additional weakness was absence of design expertise in the team and a few half-hearted attempts made to outsource the activity were not fruitful perhaps because of the lack of significant commercial interest for such activities.

Several reasons for the long project duration are summarised below:

- Long time taken for identification of the deliverable as a product and not as a simple process.

- Absence of a well-defined product process for quite some time.

- Absence of design expertise in the team as well as proper inhouse facilities to introduce the identified design features efficiently and effectively in the product.

- Poor documentation in the early stages of the project.

- Absence of good knowledge of rural areas and their requirements to start with

- Not enough clarity on the safety aspects of the filtered water for quite some time.

- Absence of a concurrent approach to project management.

- Considerable cultural difference between this activity and the other core activities of the centre.

- Overcoming the hangover related to excessive R\&D and hightechnology orientation.

- Inadequate communication from the top management to the project team for quite some time about what is expected from this project and which transfer options the management prefers. 
In the absence of proper guidelines for design, the design aspects took considerable time involving several trials.

Concurrent approach is considered by (Hull, 2000) as the most important single factor for fast and successful commercialisation of R\&D ideas. In the present case, the activity was completely serial. In fact concurrency was never thought of at any stage of the project because generally the resource deployment was very limited. Concurrency demands commitment of more up-front resources and without a defined process this is not easily possible. Process definition took place only in the latter stages of the project.

Some suggestions for an improved process for better time to market can be as follows. Get clarity on corporate management's expectations of this project at the earliest preferably by identifying different scenarios and presenting these to the management. Get commitment of resources and time based on a defined process. After the prototype trials, carry out design (preferably through outsourcing), process standardisation (including establishing realistic tolerances), establishing financial models and identification of critical dependency for transfer simultaneously. Implement technology transfer. Figure 6 indicates an improved flow chart, which includes carrying out several of the tasks indicated above simultaneously to reduce the cycle time.

In projects of this nature which are deceptively simple, it was also found difficult to assess the contribution of the people involved at various stages of the project. The tendency to credit only the initial invention and the final act of putting the product into the field as important tasks is high in view of their high visibility. In such cases, it will be useful to judge the contributions based on the extent of learning that has been put into the project at every stage as suggested by David Sheasley (2000), introducing the "learning objectives metric" to track the progress of R\&D projects. Definite learning objectives can be defined for each process step and satisfactorily achieving these objectives can be considered as a contribution.

\section{Issues related to sustainability}

One of the key strategies of this project is to transfer the filtermaking technology to the villagers so that they can make a sustainable livelihood out of it, if possible.

"A livelihood is sustainable when it can cope with and recover from stresses and shocks and maintain and enhance its capabilities and assets both now and in the future, while not undermining the natural resource base" (Farrington et al., 1999).

Sustainability in the presently proposed model can be achieved due to the replacement market which exists forever for the filters once the filter is in use in rural households. The scope to use the filter by several households depends upon the seriousness of the need in that region, level of awareness, affordability and the village density with respect to the location of the filter production centre. Low village density regions with relatively low levels of population may not achieve the critical mass of activity for sustainability because the activity gets 'stressed ' due to large transport distances. Large transport distances may also arise for the critical raw material such as rice husk ash if the production centre is far from a rice-growing locality.

Sustainability also depends on ease of access to financial capital and the policies towards credit in the rural banking sector. Also, powerful local landlords having the advantage of financial capital may dominate and control the production centres. In such regions, the objective of developing sustainable livelihood programs for the poor is difficult to materialise.

The livelihood outcomes in the present case are: more income, increased well-being because of improved health and reduced vulnerability to water-borne diseases which are seasonal. Alleviation of poverty in the broader sense means addressing issues other than just mere income (Farrington et al., 1999). In the present case, it is health and general well being.

"The prime indicator of success of any kind of activity - be it for a profit enterprise or for a non-profit charity - is customer satisfaction. In addition to customer satisfaction, success related to long-term viability and sustainability of the enterprise depends upon three fundamental success factors: profitability, competitiveness and sustainable growth in created value. The three together constitute value. While a profitable and competitive venture may survive and stay in business for a while, success over an extendable period of time is always identified with growth in value " (Pall, 1999).

Most of the rural development initiatives so far carried out by different agencies (national as well as international) in India suffer from lack of sustainability. Sustainability in the present case is expected from the need for periodic replacement of the filter element which does not take place automatically even in urban societies. The rural entrepreneur has to know how to constantly sustain this need.

The livelihood programs need not be confined to individuals. They could be for a team which could pool its resources and labour. For example, in the present case, one person could be charged with the responsibility of material procurement, a $2^{\text {nd }}$ one with the cleaning process of the ash, a $3^{\text {rd }}$ one with container preparation, a $4^{\text {th }}$ one with the filter production and the $5^{\text {th }}$ one for sale and maintaining accounts and distribution of income. In fact, a complete family can be involved in various activities of the process to have a sustainable living.

\section{Lessons learnt}

- Introduction into the field of even a simple-looking idea can be time-and-resource consuming, more so if the end use is for rural needs.

- It is useful to recognise the several steps involved in taking an R\&D idea to the field and invest resources accordingly.

- Following a process helps the way work is done even if it is for a simple rural technology product.

\section{Summary}

Providing safe drinking water to the rural poor at an affordable cost needs novel technical, managerial and financial solutions. The paper particularly discusses the steps involved in introducing a technical solution into the field highlighting the importance of the underlying process for carrying out such an activity successfully. It also highlights several pitfalls that may occur in the management of such projects and the importance of an appropriate strategy for sustainability.

\section{Acknowledgement}

The work process as described in this paper was evolved based on the patient laboratory and field work of four of the author's colleagues namely Dr KK Meher, Mr Marco, Mr Vivek Ganvir and 
Ms Keya Biswas. The author acknowledges their contribution. This work would not have been possible without the strong support of Tata Consultancy Services, India and the two successive directors of TRDDC, Prof EC Subbarao and Prof Mathai Joseph. The author is grateful to them all. Prof Subbarao reviewed the manuscript and gave helpful suggestions for improvement. Mr TK Rao's comments on the first manuscript were also helpful. Prof Mathai Joseph gave the necessary fillip in the later stages of the project to accelerate its progress towards introduction into the field.

\section{References}

FARRINGTON J, CARNEY D, ASHLEY C and TURTON C (1999) Sustainable livelihoods in practice - Early applications of concepts in rural areas. ODI Natl. Resour. Perspect. 42 (6) 1-12.

FRANKEL RJ (1979) Operation of the coconut fiber/burnt rice husks filter for supplying drinking water to rural communities in South East Asia. AJHP 69 (1) 75-76.
HULL F(2000) Idea Generation and Commercialization in $R \& D$ Laboratory Organizations World Scientific Publishing Company, Inc; NJ 07661 (USA).

HUNTWORK PK, MUZZEY DW, PIETRAS CM and WIXON DR (Fall, 1993) Changing the rules - A pragmatic approach to product development. Digital Tech. J. 5 (4) 18-35.

KUPUA LONO KAHWMA AO (1998) Don't Drink the Water - The Essential Guide to the Contaminated Drinking Water and What You Can do About it. Kali Press.

MATHYS A (2000) Water supply in underprivileged areas. New World Water 2000. Sterling Publications Limited, London. 32-34.

MEHER KK and PRASAD VCS ( 1999) (Filed for Indian Patents,1999) A Rice Husk Ash Based Domestic Water Filter.

PALL GA (1999) The Process Centred Enterprise - The Power of Commitments. St. Lucie Press, NY.

RAO CS (1991) Environmental Pollution Control Engineering. Wiley Eastern Limited. 129.

SHEASLEY WD (2000) Taking an options approach to new technology development. Res. Technol. Manage. 43 (6) 37-43.

SUNDARAM SK, MEHER KK and KAPUR PC (1997) (Filed for Indian Patents, 1997) A Rice Husk Ash Based Domestic Water Filter. 